\title{
Tafatolu (three-sides): A Samoan research methodological framework
}

Alesana Fosi Palaamo, Malua Theological College, Samoa

\begin{abstract}
INTRODUCTION: A Samoan research methodological framework called Tafatolu (threesides) involves the synthesis of three key parts considered as valuable to any research a contemporary academic approach to research, a cultural approach, and the self that represents the researcher's perspectives and positioning within the project. The rationale behind the Tafatolu methodological framework is to provide an integration of Western and Samoan perspectives to research that incorporates the cultural values and practices of the target population, as well as of the researcher.
\end{abstract}

METHOD: The researcher's doctoral study that conceptualised, articulated, and used the Tafatolu methodological framework involved the synthesis of a contemporary academic approach to research (qualitative approach), with a cultural approach (a Samoan metaphor fetu'utu'una'i muniao - manoeuvring a fisher's rod), merged with the researcher's own input into doing research (positioning as an insider/outsider researcher). Specifically, the Tafatolu methodological framework guided the researcher's study in its methodology, methods, and the analysis of data.

IMPLICATIONS: The Tafatolu methodological framework proposed and discussed in this paper provides a way to integrate western and contemporary academic approaches to research, with indigenous and cultural approaches. The fusion of its underlying concepts a contemporary academic approach, a cultural approach, and the self - can accommodate both the context of the targeted populations under review, as well as the context of the researcher.

KEYWORDS: Tafatolu; three-sides; research methodology; qualitative research; vā; relational space; Samoa; self

Qualitative research methods parallel how most Samoans share their knowledge and understandings of the world around them. In particular, qualitative research methods involve the collection, analysis, and presentation of narrative information (Teddlie \& Tashakkori, 2009). McLeod (2001) describes qualitative research in the following way:
Qualitative research is a process of careful, rigorous inquiry into aspects of the social world. It produces formal statements or conceptual frameworks that provide new ways of understanding the world, and therefore comprises knowledge that is practically useful for those who work with issues around learning and adjustment to the pressures and demands of the social world. (p. 3)
AOTEAROA

NEW ZEALAND SOCIAL WORK 30(4), 19-27.

CORRESPONDENCE TO: Alesana Fosi Palaamo alesanapalaamo@yahoo. com.au 
There are many nuances in the Samoan language that contribute to how Samoans see, understand, and interpret the world. Metaphor and language are important tools of communication for Samoans. Non-verbal communication is also valuable - eye contact, a smile, a handshake, how one walks into a room and how one sits - such non-verbal communication can determine the level of engagement and, in this instance, the level of active participation in research. Qualitative research methods provide an overarching guide to investigate populations including Samoans. This paper adds to the available qualitative research methods and presents a framework that allows for components familiar to both the research participants and the researcher.

An interpretive theory of qualitative research known as phenomenology is applicable to Samoans in developing meaning in their lives. Phenomenology as a philosophical approach to qualitative research was founded by the German mathematician Edmund Husserl (1859-1938), who understood consciousness to be based on the meaning of the individual's experiences (Reiners, 2012). This theory of interpretation requires the researcher to work with the data attained through the phenomenological inquiry, to interpret the material that emerged by reflecting on one's own experiences (Morse, 1994).

An example of seeking understanding of the individual's experiences through phenomenology can be linked to Samoans who often make meaning from their lived experiences of $f a^{\prime} a S a m o a$ - the culture and traditions of Samoa. Knowledge and learning for Samoans are practical phenomena (Tuisuga-le-taua, 2011) that are often shared through language and metaphors (Tui Atua, 2003). The theory of knowledge for Samoans is also understood through storytelling (Krämer, 1994) where culture and traditions and knowledge of honorific titles for families, villages and districts are passed onto the following generations through riddles (Tui Atua, 1994), metaphors and proverbs. As some authors have alluded to, understanding the lived experiences of fa'aSamoa give meaning to how Samoans behave and interact with each other, as well as differentiating island-born Samoans from New Zealand-born Samoans (Anae, 1998; Mailei, 2003; Tiatia, 1998).

\section{Pacific methodologies}

Pacific and Samoan research methodologies are widely used when researching populations from these regions. An example is Talanoa, a Pacific methodology that involves a talk, a conversation and exchange of ideas through face-to-face encounters that are both formal and informal where Talanoa creates knowledge (Vaioleti, 2006). Talanoa is used for discussions between individuals as well as for group dialogue. Further, the Ula methodology (Sauni, 2011) accommodates an equal relationship between researcher and participant to allow for the free expressions of beliefs and values. This Samoan research methodology accentuates an equal relationship between researcher and participant.

A widely used Samoan research methodology is Fa'afaletui. Various components of this methodology have been used by researchers investigating Pacific people including Samoans and their issues, located within the region (McCarthy, Shaban, \& Stone, 2011; SuaaliiSauni \& Fulu-Aiolupotea, 2014). Fa'afaletui uses the metaphor of the traditional practice of weaving. This practice involves the plaiting together of sundried strands of the leaves from the pandanus tree (laufala) to create various household items such as fala (a mat). The most appropriate laufala are selected and used in the process of weaving, to generate a fala that meets its intended design. Fa'afaletui uses the same principle of selecting the best laufala by interweaving various perspectives gathered about the self to offer a Samoan perspective of self as being relational (Tamasese, Peteru, Waldegrave, \& Bush, 2005).

The space in between people develops from an understanding of a relational self 
for Samoans (Tamasese et al., 2005) and communal instead of being an individual self. $V \bar{a}$ (relational space, or the space-inbetween) for Samoans is a concept that identifies and defines culturally appropriate and inappropriate behaviours (LilomaiavaDoktor, 2009); breaching these inherent $v \bar{a}$ would hinder relationships within such contexts. Teu le $v \bar{a}$ (Anae, 2010) is a Samoan research methodology that identifies the reciprocal relationships or the space between people as sacred, those that need to be nurtured and tidied when these relationships become unsacred. Teu le vā deals with the concept of maintaining and nursing $v \bar{a}$.

\section{The study}

The researcher's doctoral study conceptualised and used the Tafatolu methodological framework as its methodology (Pala'amo, 2017), and is reported here. The study investigated the counselling practices of ministers in Samoa also known as pastoral counselling and the relevance and transformation of such practices when influenced by a concept identified as a changing Samoan self. The researcher himself is a minister. The study presented the voices of 34 Samoan participants living in Samoa that included ministers, ministers' wives, matai (titleholders), Aotearoa New Zealand born Samoans, church members, and service users of a domestic violence agency. Participants shared their expectations of being counselled as well as counselling others, together with reflections concerning effective and ineffective counselling practices.

The study used one-to-one, semi-structured qualitative interviews, to investigate the social worlds of Samoan ministers and their wives, and those who used their pastoral counselling services. This form of interviewing allows flexibility for the researcher to explore issues raised through participants' responses (Ryan, Coughlan, \& Cronin, 2009), rather than following a structured and rigid schedule of explicit questions. The alternative, using focus group interviews, was also considered for the study. By using focus groups, some silent voices amongst the groups are expected (Kitzinger, 1995), even if the groups were aligned for ministers only, matai only and so forth - some voices will dominate and overpower others. Culturally, for Samoans, using group interviews may not be the best way to gather knowledge. To avoid this potential tension, one-to-one interviews were employed.

As part of ensuring the safety and comfort of all participants, women who expressed their interest in an interview were offered the option of having the researcher's co-interviewer, a woman colleague, conduct the interview alone. It has been documented that gender matching may be required for certain qualitative interviews, especially when the interviews discuss domestic violence with women (Byrne, 2004). It was important to provide a safe environment for participants during the interviews, especially if some felt uneasy speaking to a minister about sensitive issues.

The findings from the study included the development of conceptual frameworks to understand pastoral counselling and the concept of a changing Samoan self, from multiple perspectives.

\section{The Tafatolu methodological framework}

The Tafatolu methodological framework is presented as an inverted triangle with each of its sides representing three parts considered as valuable to any research - a contemporary academic approach to research, a cultural approach, and the self that represents the researcher's perspectives and positioning within the project. The following, Figure 1, illustrates the framework:

One side of the Tafatolu framework presents a contemporary academic approach to research. The contemporary academic approaches incorporate quantitative (e.g., Teddlie \& Tashakkori, 2009), qualitative (e.g., Taylor, Bogdan, \& DeVault, 2016) or mixed methods methodologies (e.g., Teddlie \& Tashakkori, 2009). 
Contemporary academic approach

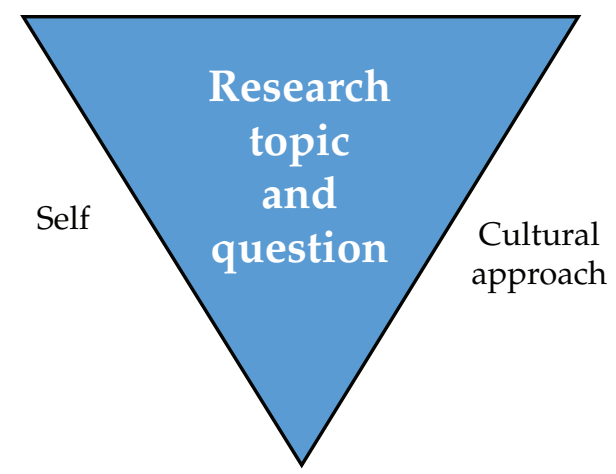

Figure 1. Tafatolu methodological framework.

These dominant methodologies in academic research are predominantly modelled on liberal humanist cultural values, and the values that inform these approaches may be incompatible with some cultures. Therefore, these contemporary academic approaches need to be infused and adapted to the values for any given culture in order to be relevant to the group being studied. This is part of the rationale for the inclusion of a cultural approach in the Tafatolu methodological framework.

A cultural approach to the research is another side of the Tafatolu methodological framework. Such an approach includes any indigenous methodology that has been developed and widely used by researchers specifically for the communities being investigated. The cultural component of the Tafatolu framework can also be a proverb or a metaphor familiar to the group being studied. The benefits of the inclusion of a cultural dimension to the research methodology are two-fold: (i) firstly for the participants, to encourage and attract prospective participants to take part in the research, by using imagery and concepts they are familiar with; and (ii) for the researcher, to help develop rapport with participants to elicit relevant data to meet the project objectives.

The third and final side of the Tafatolu methodological framework involves the self, which includes what the researcher brings to the project. More specifically, the self includes the positioning of the researcher along an insider-outsider continuum (Hellawell, 2006), as the research topic often concerns the lived experiences of the researcher to a greater or lesser extent. The movement along an insider-outsider continuum towards the outsider positioning of the researcher, signals that the researcher is a non-member of the group being studied (Dwyer \& Buckle, 2009). Further, favouring an outsider positioning suggests that the researcher is not, a priori, familiar with the setting and people under investigation (Hellawell, 2006) allowing for objectivity from the researcher. Promoting an insider positioning along such a continuum means the researcher has acceptance by participants that may lead to more open discussions and depth in the data collected (Dwyer \& Buckle, 2009). As an insider researcher, there will be lived experiences which inform the worldview of the researcher that the researcher brings into the project that need to be acknowledged and addressed. There may be times when the researcher is positioned as both outsider and insider (Hellawell, 2006; Kusow, 2003), during different stages of the project, and shifting from one position to the other is required.

In addition to the researcher's positioning at the self side of the Tafatolu framework, the participant as well must consider positioning upon the insider-outsider continuum. When articulating the lived experiences of $f a^{\prime} a$ Samoa in the study that this paper reports on, an insider positioning by the research participant is suggested with practices that align with the culture and traditions and the way of life for Samoans. For the participant who appears far removed from the culture and traditions of Samoa and the lived experiences of fa'aSamoa, this implies an outsider positioning is held by the participant. The positioning of the research participant in this instance is determined by the degree of involvement with a way of life that aligns with the culture and traditions of Samoans. 
At the centre of the Tafatolu methodological framework (presented as an inverted triangle), is the research topic, including its research question. All three sides of the Tafatolu framework - the contemporary academic approach, the cultural approach, and the self - contribute to a respective way of knowing. Collectively, these approaches provide a methodology to develop answers to the research question at the core of the project. The sections that follow demonstrate the application of this Samoan methodological framework to research.

\section{Applying the Tafatolu methodological framework}

The application of the Tafatolu methodological framework to any research project is directed to its methodology, methods, and the analysis of data. For the study that this paper reports, the Tafatolu methodological framework was firstly applied to its methodology. This culturally appropriate methodological framework for Samoans involved a qualitative approach (contemporary academic), fused with the understanding of a Samoan metaphor fetu'utu'una'i muniao (cultural), from a researcher positioning (self). Secondly, the Tafatolu methodological framework was applied to the methods used. This approach included one-to-one qualitative interviews (contemporary academic), appropriate Samoan practices and language used (cultural), and acknowledging the concept of $v \bar{a}$ - relational space (self). Finally, the Tafatolu methodological framework was applied to the analysis of data, and included thematic analysis (contemporary academic), Fa'afaletui Samoan methodology (cultural), and interpretivism (self). Fa'afaletui (weaving together of knowledge) was used to weave together various perspectives and understandings of pastoral counselling practices for Samoans, and the concept of a changing Samoan self. Interpretivism, that places the story being told and its intended audience at the core of where meaning can be drawn (Geertz, 1973), was used for its parallel to hermeneutics, the interpretation of meaning from Biblical text (Osmer, 2008), and for its link to the researcher's insider positioning as a minister.

\section{Cultural approach: Fetu'utu'una'i muniao - manoeuvring a fisher's rod}

An understanding of the Samoan metaphor fetu'utu'una'i muniao (manoeuvring a fisher's rod) provided a cultural dimension to the methodology used in the study. The phrase itself is derived from the Samoan practice of traditional canoe fishing for the bonito fish. Bonito fishing traditionally involves two operators in the canoe who are men; women are involved in other types of fishing (Armstrong, Herdrich, \& Levine, 2011). However, roles that previously were gender-specific for Samoans are now no longer clearly defined. Understanding this metaphor is not intended to be genderspecific for men only; women are just as skilful in assuming the roles specified in this method of fishing.

Bonito fishing has a rower located in the centre of the canoe, and a fisher at the rear (stern) of the canoe who manipulates the fishing rod. The moment the fisher at the rear anticipates the bonito fish taking the hook, he abruptly manipulates (fetu'utu'una'i) the rod in a forward motion pulling the traditionally woven string called afa out of the sea with the bonito fish attached to its hook, passing over or around the rower in the middle of the canoe. Muniao in the metaphor refers to the wooden fishing rod holder attached to the canoe. The fisher's rod must be manipulated precisely for a desirable outcome. The rower in the middle of the canoe must steady the canoe, while simultaneously anticipating the swinging bonito fish so that the fish lands into the middle of the canoe. A successful catch is when the bonito fish lands into the centre of the canoe. The partnership of rower and fisher is necessary for a successful catch the rower steers the canoe to where the bonito fish may be found, and keeps the boat upright and balanced, while the fisher's primary task is to operate the fishing rod. 
However, when unsuccessful, the bonito fish will collide with the rower in the centre of the canoe and may fall back into the sea and be lost.

This metaphor explains the use of one-toone interviews as a research method. The researcher and participant work together to develop an understanding of pastoral counselling and a changing Samoan self through the interviews, just like the fisher and rower work together in bonito fishing. The researcher is the fisher with the rod; while the participant is the rower who navigates where the discussions lead. A successful interview between researcher and participant is where both co-operated to develop insight and understanding - a successful catch in terms of bonito fishing through fetu'utu'una'i muniao.

\section{Self: vā (relational space)}

$V \bar{a}$ (relational space) as one side of the Tafatolu methodological framework when applied to the methods used in the study, means that certain cultural methods used would acknowledge and account for $v \bar{a}$. Fa'atūlima - the sharing of hands (literally) - is a Samoan cultural practice used during the interviews that addressed $v \bar{a}$ between participants and the researcher. When Samoans meet for any given reason, after the guest has been greeted with a handshake and then seated, the host then welcomes the guest citing honorific titles and designations. If known by the host, the acknowledgement of the guest's village and family titles are also included. The guest responds by addressing any honorific titles and designations held by the host. After such verbal exchanges, only then will the reason for the visit be expressed. Fa'atūlima as a Samoan greeting practice extends beyond the literal shaking of hands - it is a practice that sets $v \bar{a}$ between the guest and host through acknowledging titles and designations for both the guest and host. All interactions from that point forward will be guided by $v \bar{a}$ that has been understood through the process of fa'atülima. This cultural method set the scene for the interviews, and developed rapport with participants when any titles they had were acknowledged. It was a cultural practice that assisted in engaging participants, affording them respect and honour prior to the start of the interviews.

As an oratorical and communal people, relationship-building and the maintenance of relationships are important to ensure harmonious communal living. $V \bar{a}$ therefore assists with relationship-building for Samoans. Members of each household have their assigned responsibilities and duties to perform, and each one understands their part in the larger familial and village setting. Matai and elders, for example, are regarded as leaders of the family, while the young men often are responsible for cooking duties. Fa'aSamoa itself assists in keeping such relationships intact, where appropriate practices and behaviours for Samoans have been laid down through the generations, according to the traditions and customs of Samoa. The acknowledgement and management of $v \bar{a}$ plays a vital role in harmonious living for Samoans.

\section{Contemporary academic approach: thematic analysis}

The application of the Tafatolu methodological framework in reference to the analysis of data involved thematic analysis. This strategy occupied the contemporary academic side of the Tafatolu framework. Thematic analysis is the process where both implicit and explicit ideas found in the data are grouped together into themes (Braun \& Clarke, 2006). This method of analysis identifies key patterns that have come forth from the data collected.

Thematic analysis can either be inductive (where themes generated are linked to the data), or in a theoretical or deductive way, with a theoretical interest by the researcher in mind (Braun \& Clarke, 2006). Specifically, for the study reported herein, analysis of the data needed to be dynamic, similar to the way the Samoan self is dynamic. Since 
a major part of the investigation in the study involved the concept of a changing Samoan self, a dynamic approach to analysis aligned with the concept of change. Further, the Samoan language is rich with nuances where the same word can have several interpretations. The variety of interpretations is based on briefings and the emphasis given to particular vowels, and how the hearer hears the spoken word. The meanings of certain Samoan words that participants used were clarified with participants during the interviews, and also later with a matai who proof-read transcriptions for any grammatical corrections to the language reported. Due to these reasons, employing a flexible approach in the analysis of the data was necessary that included an inductive approach to thematic analysis.

One of the initial processes that preceded any thematic analysis, was transcribing the digital audio recordings of the interviews. Verbatim transcripts were developed from the audio recordings of the interviews and since the majority of interviews were done in Samoan, transcripts also were predominantly in Samoan.

An important consideration about the process of analysis was the language used. As mentioned earlier, the interviews and thus the transcriptions mostly were in Samoan. The analysis that led to generated codes and ultimately the themes that emerged were undertaken from the Samoan transcriptions developed. The benefit for the researcher in working closely with the data as both the primary interviewer and transcriber of a significant proportion of the data, presented many opportunities to identify key areas of interest during the interviews and also during transcribing. The thematic analysis process used in the study followed the process of thematic analysis suggested by Braun and Clarke (2006) and was undertaken in four steps: (1) transcribing the digital audio recordings while simultaneously classifying areas of interest; (2) reading the verbatim transcriptions, creating and revising notes previously made; (3) using OneNote as a codebook to group and categorise codes that emerged from the transcriptions; and (4) comparing, revising, and merging similar codes into groups that became the underlying themes from this project. The theoretical models of information that developed from the process of analysis became the underlying themes from the data.

Assisting the process of grouping common data patterns into themes is the use of coding. Coding is identified as a way to decontextualize text (transcriptions) and formulate useful and meaningful coded material (Hesse-Biber, 2017). Ideas and theories are identified either inductively (that is, driven and generated by the data into codes), or deductively (beginning with theory and the codes formulated either confirm or deny the theory) (HesseBiber, 2017). OneNote computer software application was then used as a codebook in working with the codes generated.

\section{Conclusion}

The Tafatolu methodological framework proposed and discussed in this paper, provides a way to integrate western and contemporary academic approaches to research, with indigenous and cultural approaches. The research implications of this framework are that the fusion of its underlying concepts - a contemporary academic approach, a cultural approach, and the self - accommodate both the context of the targeted populations under review, as well as the context of the researcher. Although the study that conceptualised, developed, and used the Tafatolu methodological framework is about pastoral counselling practices for Samoans, as a framework for research it may also appeal to researchers exploring various issues from other indigenous and Pacific populations and communities. The Tafatolu methodological framework as presented herein is introduced alongside the available Pacific and Samoan research methodologies, and is proposed as a way to guide research projects from these regions. 


\section{Acknowledgements}

This paper reports the methodology used in the researcher's doctoral study in the School of Social Work at Massey University New Zealand under the supervision of Professor Mark Henrickson, Dr Lily George, and Dr Catherine Cook. The doctoral study mentioned was supported in full under a scholarship by the Ekalesia Fa'apotopotoga Kerisiano Samoa (EFKS) also known as Congregational Christian Church Samoa (CCCS) as part of its staff development programme for Malua Theological College in Samoa.

\section{References}

Anae, M. (1998). Fofoa $i$ vao ese: The identity journeys of NZ-born Samoans. (Unpublished doctoral dissertation), The University of Auckland, Auckland, New Zealand. Retrieved from https://researchspace.auckland.ac.nz/ handle/2292/66

Anae, M. (2010). Research for better Pacific schooling in New Zealand: Teu le va-a Samoan perspective. Mai Review, 1, 1-24. Retrieved from http://ojs.review.mai. ac.nz/index.php/MR/article/view/298/395

Armstrong, K., Herdrich, D., \& Levine, A. (2011). Historic fishing methods in American Samoa. U.S. Department of Commerce. Retrieved from https://www.pifsc.noaa.gov/ library/pubs/tech/NOAA_Tech_Memo_PIFSC_24.pdf

Braun, V., \& Clarke, V. (2006). Using thematic analysis in psychology. Qualitative Research in Psychology, 3(2), 77-101.

Byrne, B. (2004). Qualitative interviewing. In C. Seale (Ed.), Researching society and culture (3rd ed., pp. 179-192). London, United Kingdom: Sage Publications.

Dwyer, S. C., \& Buckle, J. L. (2009). The space between On being an insider-outsider in qualitative research. International Journal of Qualitative Methods, 8(1), 54-63.

Geertz, C. (1973). The interpretation of cultures: Selected essays (Vol. 5019). New York, NY: Basic books.

Hellawell, D. (2006). Inside-out: Analysis of the insideroutsider concept as a heuristic device to develop reflexivity in students doing qualitative research. Teaching in Higher Education, 11(4), 483-494. Retrieved from http://dx.doi.org/10.1080/13562510600874292

Hesse-Biber, S. N. (2017). The practice of qualitative research: Engaging students in the research process (3rd ed.). Los Angeles, CA: Sage Publications.

Kitzinger, J. (1995). Qualitative research. Introducing focus groups. British Medical Journal, 311(7000), 299-302. Retrieved from http://www.ncbi.nlm.nih.gov/pmc/articles/ PMC2550365

Krämer, A. (1994). The Samoa Islands: An outline of a monograph with particular consideration of German Samoa (T. Verhaaren, Trans. Vol. 1). Auckland, New Zealand: Polynesian Press.

Kusow, A. M. (2003). Beyond indigenous authenticity: Reflections on the insider/outsider debate in immigration research. Symbolic Interaction, 26(4), 591-599.
Retrieved from http://onlinelibrary.wiley.com/doi/10.1525/ si.2003.26.4.591/full

Lilomaiava-Doktor, S. (2009). Beyond "migration": Samoan population movement (malaga) and the geography of social space (vā). The Contemporary Pacific, 21(1), 1-32. Retrieved from http://ezproxy. massey.ac.nz/login?url=http://search.ebscohost.com/ login. aspx?direct=true \&db=edspmu\&AN=edspmu. S152794640810017X\&site=eds-live \&scope=site

Mailei, F. D. T. (2003). E lele a le toloa a e maau lava i le vai. In P. Fairbairn-Dunlop \& G. S. Makisi (Eds.), Making our place: growing up PI in New Zealand (pp. 222-231). Palmerston North, New Zealand: Dunmore Press.

McCarthy, A., Shaban, R., \& Stone, C. (2011). Fa'afaletui: A framework for the promotion of renal health in an Australian Samoan community. Journal of Transcultural Nursing, 22(1), 55-62. Retrieved from http://journals. sagepub.com/doi/pdf/10.1177/1043659610387154

McLeod, J. (2001). Qualitative research in counselling and psychotherapy. London, United Kingdom: Sage Publications.

Morse, J. M. (1994). "Emerging from the data": The cognitive processes of analysis in qualitative inquiry. In J. M. Morse (Ed.), Critical issues in qualitative research methods (pp. 23-43). Los Angeles, CA: Sage Publications.

Osmer, R. R. (2008). Practical theology: An introduction. Grand Rapids, MI: William B. Eerdmans.

Pala'amo, A. (2017). Fetu'utu'una'i le va Navigating relational space: An exploration of pastoral counselling practices for Samoans. (Unpublished doctoral dissertation), Massey University, Albany, New Zealand). Retrieved from https://mro.massey.ac.nz/ handle/10179/11813

Reiners, G. M. (2012). Understanding the differences between Husserl's (descriptive) and Heidegger's (interpretive) phenomenological research. Journal of Nursing \& Care, 1(5), 1-3. Retrieved from http://dx.doi. org/10.4172/2167-1168.1000119

Ryan, F., Coughlan, M., \& Cronin, P. (2009). Interviewing in qualitative research: The one-to-one interview. International Journal of Therapy \& Rehabilitation, 16(6), 309-314. Retrieved from http://ezproxy.massey. ac.nz/login?url=http://search.ebscohost.com/login.as px?direct=true $\& d b=c c m \& A N=105355792 \&$ site $=$ edslive \&scope $=$ site

Sauni, S. L. (2011). Samoan research methodology: The ula-a new paradigm. Pacific-Asian Education, 23(2), 53-64. Retrieved from https://cdn.auckland.ac.nz/assets/ education/about/schools/crstie/docs/2012/PAE_23_2 final_11.pdf\#page $=53$

Suaalii-Sauni, T., \& Fulu-Aiolupotea, S. M. (2014). Decolonising Pacific research, building Pacific research communities and developing Pacific research tools: The case of the talanoa and the faafaletui in Samoa. Asia Pacific Viewpoint, 55(3), 331-344. Retrieved from http://eds.b.ebscohost.com.ezproxy.massey.ac.nz/eds/ pdfviewer/pdfviewer?vid=1\&sid=9ba2c5a2-14f6-4fab8eb5-7edab8fdea90\%40sessionmgr103\&hid=111

Tamasese, K., Peteru, C., Waldegrave, C., \& Bush, A. (2005). Ole taeao afua, the new morning: A qualitative investigation into Samoan perspectives on mental health and culturally appropriate services. Australian and New Zealand Journal of Psychiatry, 39, 300-309. 
Taylor, S. J., Bogdan, R., \& DeVault, M. (2016). Introduction to qualitative research methods: $A$ guidebook and resource. Hoboken, NJ: John Wiley \& Sons.

Teddlie, C., \& Tashakkori, A. (2009). Foundations of mixed methods research: Integrating quantitative and qualitative approaches in the social and behavioral sciences. Los Angeles, CA: Sage Publications.

Tiatia, J. (1998). Caught between cultures: A New Zealandborn Pacific Island perspective. Auckland, New Zealand: Christian Research Association.

Tui Atua, T. T. T. E. (1994). The riddle in Samoan history. Journal of Pacific History, 29(1), 66-79.

Tui Atua, T. T. T. E. (2003). In search of meaning, nuance and metaphor in social policy. Social Policy Journal of New Zealand, 20, 49-63. Retrieved from http://www. msd.govt.nz/documents/about-msd-and-our-work/ publications-resources/journals-and-magazines/socialpolicy-journal/spj20/20-pages49-63.pdf

Tuisuga-le-taua, F. A. (2011). O le Tofa liliu a Samoa: A hermeneutical critical analysis of the cultural-theological praxis of the Samoan context. (Unpublished doctoral dissertation), Melbourne College of Divinity, Melbourne, Australia. Retrieved from http://repository.divinity.edu. au/900/1/2011Th(PhD)_Tuisuga,FA_O_Le_Tofa_ Liliu_A_Samoa.pdf

Vaioleti, T. M. (2006). Talanoa research methodology: A developing position on Pacific research. Waikato Journal of Education, 12, 21-34. Retrieved from http://hdl. handle.net/10289/6199 